\title{
Nutrition and oral health
}

\author{
Shaik Ali Hassan \\ Dental Surgeon, Manav Rachna Dental College, Faridabad, India \\ *Corresponding Author: Shaik Ali Hassan \\ Email: alishaikhassan@gmail.com
}

\begin{abstract}
Diet assumes a significant job in anticipating oral illnesses including dental caries, dental erosion, developmental deformities, oral mucosal disease and, to a lesser degree, periodontal problem. Undernutrition builds the seriousness of oral mucosal and periodontal ailments and is a contributing variable to dangerous noma. Under nutrition is related with formative imperfections of the lacquer which increment helplessness to dental caries. Dental erosion is seen to increase. Proof recommends that soda gas, a significant wellspring of acids in the eating routine in nations, are a significant causative factor. Persuading proof from test, creature, human observational and human mediation contemplates shows that sugars are the principle dietary factor related with dental caries. Dietary advice for the prevention of oral diseases has a part of routine patient education. This review paper suggests that the nutrition training has to be given by dentist for patients to reduce the illness related to oral mucosa.
\end{abstract}

Keywords: Nutrition, vitamin A and D, dental caries, periodontal disease.

\section{Introduction}

WHO defines oral health as "a state of being free from chronic mouth and facial pain, oral and throat cancer, oral infection and sores, periodontal (gum) disease, tooth decay, tooth loss, and other diseases and disorders that limit an individual's capacity in biting, chewing, smiling, speaking, and psychosocial well being. ${ }^{1}$ Dental illnesses hinder personal satisfaction and negatively affect confidence, eating capacity and wellbeing, causing agony, uneasiness and weakened social working. ${ }^{2,} 3$ Tooth misfortune decreases the capacity to eat a nutritious eating regimen, the pleasure in nourishment and certainty to mingle. ${ }^{4,5}$.This article is planned to give an outline of the connections between diet, nourishment and oral sicknesses.

\section{Role of nutrition in periodontal disease}

Periodontal disease advances more quickly in undernourished population ${ }^{6}$ the job of nourishment in keeping up a sufficient safe reaction may clarify this perception. Periodontal disease is related with an expanded generation of receptive oxygen species which, if not treated adequately, cause harm to the host cells and tissues. ${ }^{7}$ Cancer prevention agent supplements, for instance, ascorbic corrosive (nutrient $\mathrm{C}$ ), beta-carotene and alpha-tocopherol (nutrient E) are significant cradles of receptive oxygen species and are found in numerous organic products, vegetables, grains and seeds.

\section{Role of nutrition in developmental defects of enamel}

Dietary status influences the teeth pre-eruptively, in spite of the fact that this impact is considerably less significant than the post-eruptive impact of diet. ${ }^{8}$ Lack of nutrients D,A and protein-vitality hunger are related with enamel hypoplasia and salivary organ decay, the two of which increment weakness to dental caries. Exorbitant fluoride ingestion while enamel forming (up to the age of 6 years for lasting dentition) may cause dental fluorosis.

\section{Role of nutrition in developmental in erosion}

Dental erosion is the irreversible loss of dental hard tissue that is artificially scratched away by acids in a procedure not including microorganisms. Dietary acids incorporate citrus, phosphoric, ascorbic, malic, tartaric, oxalic and carbonic acids. These acids are found, for instance, in products of the soil juices, sodas and vinegar. Observational ponders in people have indicated a relationship between dental disintegration and the utilization of various acidic nourishments and beverages, including utilization of organic product juice, soda pops, vinegar, citrus leafy foods. ${ }^{9}$ Agerelated incidents in dental erosion have been demonstrated to be more noteworthy in those with the most noteworthy admission of soda pops. ${ }^{10}$ Animal studies have indicated that products of the soil drinks cause disintegration, despite the fact that natural product juices were 3-10 times more ruinous than entire organic product. ${ }^{11}$

\section{Role of nutrition in dental caries}

In developing nations, dental caries has expanded where there has been expanded presentation to dietary sugars. Dental caries happens in view of demineralization of enamel and dentine by natural acids shaped by microorganisms in dental plaque through the anaerobic digestion of dietary sugars. ${ }^{2}$ An abundance of proof from a wide range of types of examination, including human investigations, creature tests what's more, trial contemplates has reliably indicated that sugars are the most significant factor in caries advancement. A study led on worldwide epidemiological information in the 1980s found the accessibility of sugar to represent $52 \%$, furthermore, a comparative report during the 1990 s, for $28 \%$ of the variety in levels of dental caries. ${ }^{12,13}$ In nations with a degree of sugar utilization of under 18 $\mathrm{kg} /$ individual/year, caries experience is reliably low. ${ }^{13,14}$ The decreased accessibility of sugar during the Second World 
War was reflected by a decrease in dental caries, which in this manner expanded when the limitation was lifted. ${ }^{15}$

\section{Amount of sugar that has to be consumed}

At the point when utilization of sugars is under 10 $\mathrm{kg} /$ individual/year the degree of dental caries is low. ${ }^{16}$ Research has reliably indicated that when utilization of sugars surpasses $15 \mathrm{~kg} /$ individual/year dental caries increments and strengthens (for example happens prior posteruptively and advances all the more quickly), in spite of the fact that presentation to fluoride may build the protected degree of utilization of sugars to around $20 \mathrm{~kg} / \mathrm{year} .{ }^{17} \mathrm{WHO}$ has prescribed that nations with a low admission of free sugars don't expand admission and those with higher admissions (>15-20 kg/year) expect to diminish admission of free sugars to not exactly $10 \%$ of vitality consumption (which likens to $<15-20 \mathrm{~kg} /$ year). It is likewise suggested that the recurrence of admission of free sugars is restricted to multiple times or less every day, on the grounds that over this recurrence the measures of sugars expended will in general surpass $15 \mathrm{~kg} /$ year and more significant levels of caries happen ${ }^{18}$.

\section{Conclusion}

It is been seen that a recommended dose of sugar is needed to prevent the dental caries as the sugar is the main source of dental caries. Various vitamins like vitamin $d$ and A help in the mineralization of dentin. The elimination of malnutrition will help to prevent and control developmental defects of the enamel, oral infectious diseases and periodontal disease and dental caries. Dietary goals for the prevention of all major diet-related chronic diseases, a diet that is high in fruits, vegetables and wholegrain starchy foods and low in free sugars and fat is likely to benefit many aspects of oral health including prevention of caries, periodontal conditions, oral infectious diseases.

\section{Source of funding: None.}

\section{Conflict of interest: None.}

\section{Reference}

1. World Health Organization. World Oral Health Report 2003. Published 2003. Accessed 15 February, 2018.

2. Kelly M, Steele J, Nuttall N. Adult dental health survey. Oral health in the United Kingdom 1998. London: The Stationery Office; 2000.

3. Chen M, Andersen RM, Barmes DE, Leclercq M-H, Lyttle SC. Comparing oral health systems. A Second International Collaborative Study. Geneva: World Health Organization; 1997.

4. Joshipura KJ, Willett WE, Douglass CW. The impact of edentulousness on food and nutrient intake. J Am Dent Assoc 1966; 129:1261-9.

5. Steele JG, Sheiham A, Marcenes W, Walls AWG. National diet and nutrition survey: people aged 65 years and over. Volume 2: Report of the oral health survey. London: The Stationery Office; 1998.
6. Enwonwu CO. Interface of malnutrition and periodontal diseases. Am J Clin Nutr 1995; 61 Suppl:430-6.

7. Moynihan PJ, Lingström P. Oral consequences of compromised nutritional well-being. In: Touger-Decker R, Sirois D, Mobley C, editors. Nutrition and oral medicine. New Jersey: Humana Press; 2005.

8. Rugg-Gunn AJ. Nutrition and dental health. Oxford: Oxford Medical Publications; 1993.

9. Jarvinen VK, Rytomaa I, Heinonen OP. Risk factors in dental erosion. J Dental Res.1991; 70:942-7.

10. Walker A, Gregory J, Bradnock G, Nunn J, White D. National diet and nutrition survey: young people aged 4 to 18 years. Volume 2: Report of the oral health survey, London. The Stationery Office; 2000.

11. Holloway PJ, Mellan by M, Stewart RJC. Fruit drinks and tooth erosion. British Dental J 1958; 104:305-9.

12. Moynihan PJ, Petersen PE. Diet, nutrition and the prevention of dental diseases. Public Health Nutr 2004; 7:201-26.

13. Sreebny LM. Sugar availability, sugar consumption and dental caries. Community Dent Oral Epidemiol 1982; 10:1-7.

14. Woodward M, Walker ARP. Sugar and dental caries: the evidence from 90 countries. British Dental J 1994; 176:297302.

15. Takeuchi M. Epidemiological study on Japanese children before, during and after World War II. Int Dental J 1961; 11:443-57.

16. Miyazaki H, Morimoto M. Changes in caries prevalence in Japan. Eur J Oral Sci 1996; 104:452-8.

17. Sheiham A. Sugars and dental caries. Lancet 1983; 1:282-4.

18. Rugg-Gunn AJ, Edgar WM, Geddes DAM, Jenkins GN. The effect of different meal patterns upon plaque $\mathrm{pH}$ in human subjects. British Dental J1975; 139:351-6.

How to cite this article: Hassan SA, Nutrition and ora health, J Nutr Metab Health Sci 2019;2(4):95-6. 